\title{
Gambling Marketing from 2014 to 2018: a Literature Review
}

\author{
Philip W. S. Newall ${ }^{1} \cdot$ Crawford Moodie $^{2} \cdot$ Gerda Reith $^{3} \cdot$ Martine Stead $^{2} \cdot$ Nathan Critchlow $^{2} \cdot$ Amber Morgan $^{2}$. \\ Fiona Dobbie ${ }^{4}$
}

Published online: 6 March 2019

(C) The Author(s) 2019

\begin{abstract}
Purpose of Review Legislation and technology have led to unprecedented changes in the frequency and content of gambling marketing in many countries. We build upon previous reviews by exploring research on gambling marketing from between 2014 and 2018.

Recent Findings Most literature reviewed was from the UK or Australia, with three key findings identified. First, gambling marketing is highly targeted and ubiquitous around sport, with the most popular strategies being increasing brand awareness, advertising complex financial incentives for participation and advertising complex betting odds. Second, perceptions of gambling advertising, particularly among vulnerable groups (e.g. children, problem gamblers) appear to be influenced by this targeted content. Third, emerging research suggests that awareness of gambling marketing is associated with more frequent and riskier gambling behaviour.
\end{abstract}

Summary The reviewed literature suggests that gambling marketing is targeted and influences how gambling is perceived, and that it may affect gambling-related behaviours.

Keywords Gambling advertising $\cdot$ Gambling promotion $\cdot$ Betting $\cdot$ Sports betting $\cdot$ Policy

\section{Introduction}

Changes in the media landscape in recent years have fundamentally altered gambling marketing practice. Consumers can now gamble in real-time and from almost any location. Contemporary gambling marketing now represents a multi-layered mix of mass media advertising (e.g. television), consumer marketing (e.g. price offers) and subtle marketing (e.g. sponsorship). Advertising is a key component of gambling marketing, and recent easing of

This article is part of the Topical Collection on Gambling

Philip W. S. Newall

Philip.Newall@warwick.ac.uk

1 Applied Psychology, WMG, University of Warwick, Coventry CV4 7AL, UK

2 Institute for Social Marketing, University of Stirling, Stirling, UK

3 School of Social and Political Sciences, University of Glasgow, Glasgow, UK

4 Usher Institute, College of Medicine and Veterinary Medicine, University of Edinburgh, Edinburgh, UK restrictions has seen a proliferation of gambling advertising in many countries. There is a need to examine recent evidence on the nature of this advertising and its potential effects.

Two previous reviews have provided an overview of gambling advertising research [1,2]. Binde provided a critique of different approaches to measuring the content and frequency of gambling marketing and suggested future research priorities, but focused less on the existing evidence base of gambling marketing's impact on behaviour. Parke et al. concluded that gambling advertising was portrayed as a positive, normal social activity, and that messages within these adverts promoting 'responsible gambling' would most likely be dismissed. Both reviews highlighted the methodological challenges when attempting to assess the impact of gambling marketing on gambling behaviour. In this paper, we aim to build upon these previous reviews by exploring research conducted within the past five years.

Our objectives are to review recent evidence on the following:

(i) Gambling marketing content and frequency

(ii) Consumers' gambling marketing perceptions

(iii) Gambling marketing's effect on behaviour 


\section{Methods}

Searches for peer-reviewed primary research exploring gambling marketing, and published since January 2013, were run in four academic literature databases in April 2018: Business Source Complete (EBSCOHost), Health Source (EBSCOHost), Leisure Tourism Database (CABI) and Web of Science Core Collection (Social Sciences, Arts and Humanities and Emerging Sources Citation Indexes). A further set of relevant records was found by snowballing the reference lists and from the authors' knowledge of the literature.

Primary research including secondary analysis of an existing dataset was eligible for inclusion, but editorials, conference abstracts, opinion/theoretical pieces with no primary data and literature/systematic reviews were excluded, as with any articles from 2013 that were included in the reviews by Binde or Parke et al. Search results were limited to English language only, but any type of study design (e.g. quantitative, qualitative, experimental or mixed methods) and population group were eligible for inclusion as long as they related to the research objectives. The search strategy combined terms for gambling (e.g. betting, bingo, bookmakers, casino, gambling, lottery, wager) with terms for advertising and marketing (e.g. advert, branding, commercials, consumers, digital media, marketing, online, promotions, publicity, televised). Terms were truncated to include all forms of the 'root word' including plurals.

An initial screening exercise that involved reading the records' titles only removed the records that were obviously irrelevant. The remaining record title and abstracts $(n=873)$ were screened by four reviewers (FD, PN, CM, AM). A set of 65 records were retrieved as full texts for final assessment for inclusion by the reviewers. The final set of studies $(n=46)$ met the relevancy criteria and were included for full data extraction (see Fig. 1). All of the grey literature sources cited in this review were included based on the researchers' knowledge of the literature.

\section{Gambling Marketing Content and Frequency}

A number of content analyses have explored gambling marketing and its frequency. One study found that $17 \%$ of all advertising shown around ITV's coverage of the 2018 World Cup was for gambling [3]. This study was performed by data journalists at the Guardian newspaper, and although not existing in either peer-reviewed or grey literature report, we have independently checked the dataset and found it to be of high quality. This study found that British viewers of the World Cup were shown almost 90 minutes of betting adverts during the tournament. These were confined to the advertising breaks however, as no pitch-side gambling advertising was allowed during the tournament, and no teams had gambling advertising shirt sponsors. In contrast, in the English Premier League, the number of teams with gambling shirt sponsors increased from four in 2008 to six in 2012 and ten in 2017, or half of all teams [4]. This trend is even more marked when considering a longer-term time series of shirt sponsorship, from 1992, which found that prior to 2005 less than three teams had gambling short sponsors [5].

The growth of pitch-side advertising and shirt sponsorship means that gambling marketing can also appear in sports highlights shows. Analysis of three full Match of the Day episodes (a soccer highlights shown, broadcast on a non-commercial British channel, BBC1) found an average of over 250 gambling logo exposures per episode [6]. This was more than the average number seen in full televised matches shown on a commercial broadcaster (Sky Sports), despite the likelihood of gambling advertising also appearing during commercial breaks there.

Several studies suggest that a saturation of gambling marketing around sport is not unique to the UK. An analysis of National Rugby League matches in Australia found an average of 110.7 gambling advertising episodes per match [7]. Unlike the UK, gambling marketing was not restricted to logos seen during play or commercial breaks, but was also embedded during the live commentary and during the half-time studio break via betting odds discussions [8]. This is an example of a growing trend, where gambling marketing slowly seeps into other forms of media content.

Another line of research looks at the specific themes or narratives used to promote gambling. Converging evidence from Australia [9], the UK and Spain [10] and Canada [11] shows gambling marketing frequently showing gamblers as winners. Other thematic analyses argue that sports betting advertising makes gambling appear predictable and skilful [12]. A content analysis of 280 televised Australian gambling adverts found that bright colours and humour were common features [13], a finding which has been replicated elsewhere [14].

Online gambling marketing, which is likely to grow in the coming years, can be challenging to explore systematically. First, there are a large number of sites and platforms that gambling marketing can appear on. Second, online marketing is increasingly targeted on an individual level, meaning that different people get sent different messages [15]. The targeting of gambling marketing around sport provides just one personal characteristic (being a sports fan) which might be used in the targeting of online gambling marketing. However, this means that the measurement of online gambling marketing frequency is impossible without access to targeting data, which might be held be gambling companies, media operators and marketing agencies.

Data from the UK's Gambling Commission shows that $10 \%$ of 11-16 year olds follow at least one gambling company 
Fig. 1 Preferred Reporting Items for Systematic Reviews and Meta-Analyses (PRISMA) flow diagram of the screening process

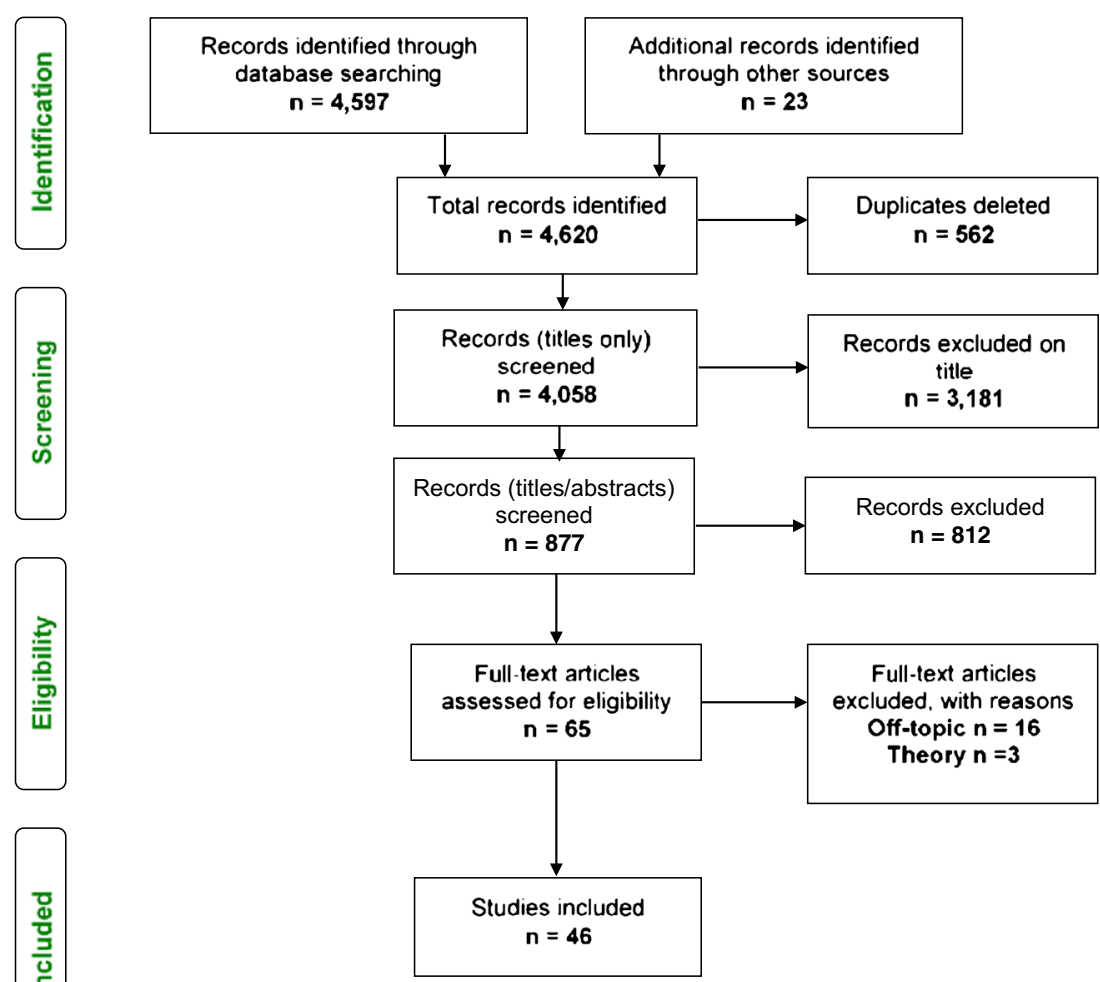

on social media [16]. One study of gambling marketing across Facebook, Twitter and Youtube found that messages could be high volume, and many messages were not clearly marked as promotional material [17]. A study with an Australian undergraduate sample found that $58 \%$ reported remembering seeing a paid-for gambling advert on Facebook in the previous year [18]. Another Australian study of 11-16-year-old basketball fans found that $55 \%$ could recall seeing gambling advertising on social media [19]. While children are also likely to be exposed to gambling marketing online, given the large number who uses new media, there is a dearth of research quantifying the extent and frequency of this. One way to approach this issue would be through gambling and marketing industry data on online advertising expenditure and targeting, although this is not currently available to researchers. Instead, the nascent literature on this topic has relied on self-reports, which provide useful insight but are based on the fallibilities of memory. One qualitative study of young people in Canada found that social casino games were an entry point to online gambling, and that advertising in these games served as an entry point to other forms of online gambling [20]. Australian youths have also been found to be exposed to social casino advertising [21].

In our view, gambling marketing can often be placed into one of three categories: (1) brand awareness, (2) financial incentives and (3) odds advertising. This categorisation scheme can be used to highlight an additional level of how gambling marketing content is targeted. As already highlighted in online marketing, gambling marketing might be targeted so that some consumers are more likely to receive a communication than others. But the content of gambling marketing can also be targeted, so that certain types of messages are more likely to be received than others. The remainder of this section highlights what is known about targeted gambling marketing content.

Brand awareness adverts are defined as any marketing message which serves to remind consumers of a gambling brand's existence, but without including any more substantive financial incentives, mentioning betting odds or promoting specific product features. Brand awareness gambling advertising can lead to a high saturation of betting logos seen during sports coverage [4-7].

Financial incentives to gamble frequently appear in advertising and can take many forms. A study from Australia found 15 distinct types, including sign-up bonuses, refer-a-friend bonuses, refunds and risk-free bets [22]. These incentives were accompanied by a lot of technical fine print and conditions. For example, money was often given as 'free bets', which would have to be gambled a specified number of times before it could be withdrawn from the account. A similar range of financial incentives have been observed in both the UK and Spain [10]. The complexity of financial incentives in gambling marketing appears to be increasing. Financial incentives used to feature primarily on sign-up bonuses, where say a 
new gambler depositing $£ 100$ might be given another $£ 50$ in bonus money. But more recent techniques seem to focus on conditional financial incentives, such as boosted odds (e.g. boosted odds of a $£ 20$ profit per $£ 1$ bet on a team which is predicted to win) and refunds (e.g. money back as a free bet on losing bets or is a salient 'close call/near-miss' outcomes occurs) [22]. All of these recent techniques could plausibly play on established psychological biases. For example, gamblers can be far more risk-seeking with money that they perceive as having won at gambling, compared with their own money, which is relevant to boosted odds [23]. Losses are especially salient compared with equivalent sized gains [24], and offering money back on losing bets could take advantage of this bias. Finally, gamblers evaluate near-miss outcomes in a biased manner and pay excessive attention to near-miss outcomes $[25,26]$. Arguably, advertised financial incentives are becoming more attuned to take advantage of these decision making errors, rather than offering gamblers incentives of true economic value.

Odds advertising features anecdotally in Australian research [7, 8], but the most rigorous studies on the types of events featuring in odds advertising have come from studies of UK soccer. Two features stand out from this research. The first feature is that odds adverts tend to be for very specific 'complex' bets, e.g. 'Thomas Müller to score first and Germany to win 3-1' [27] or 'England to win by three or more goals, Harry Kane to score, and over 11 corners' [28]. As a bet becomes more specific, the size of the potential win increases. However, bookmakers' odds are quoted so that the chances of winning decrease even more [29]. This means that the bookmaker makes a higher profit margin on complex bets than traditional simple bets, such as 'England to win' [27, 30]. Experimental evidence further suggests that soccer fans fail to correctly understand the complex bets which dominate in UK soccer odds advertising [30]. This could be argued to violate UK regulatory guidance on gambling advertising and 'limitations on the capacity to understand information' [31].

The second feature from the research on odds advertising is that advertised bets tend to involve individually intuitive events. For example, Thomas Müller was the top goal scorer in the 2014 World Cup, and Harry Kane was the top goal scorer in the 2018 World Cup. Previous psychological research indicates that people are most likely to overestimate the likelihood of a very specific event happening precisely when it involves at least one individually intuitive event [32]. Similar to our observations around advertised financial incentives, advertised complex odds seem to be taking advantage of decision making errors, rather than offering gamblers incentives of true economic value. However, it is as yet unclear whether the same psychological factors occur in odds advertising internationally and in online marketing, or how these targeted strategies affect gambling behaviour.

\section{Gambling Marketing Perceptions}

The research we find in this area is currently culturally homogenous, with most work to date coming from Australia. One exception is a general population study from Finland, where $20 \%$ felt that they had been exposed to too much gambling advertising, and $15 \%$ felt that advertising had made them gamble more [33]. These numbers were elevated in a separate clinical sample of treatment-seeking gamblers, with $68 \%$ feeling that they had been exposed to too much advertising and $35 \%$ that advertising had made them gamble more [33].

Research on Australian problem gamblers raises a number of related perceptions around gambling advertising. Problem gamblers expressed concerns around free bets or risk-free gambles, especially when these adverts were targeted via mobile phone push notifications or via email when the gambler was trying to reduce gambling frequency [34]. Gambling advertising around sport appeared to influence problem gamblers more than casual sports bettors [8, 35]. It has also been reported that problem gamblers approve more of gambling advertising than non-problem gamblers [36]. Problem gamblers also reported being attracted to in-play betting inducements, which allow gamblers to make high-frequency bets throughout a sporting event $[37,38]$. Australian rugby league fans reported being influenced by odds advertising, 'and when I see a long shot I get a little excited, so out comes my phone' [39]. A Swedish study also reported that problem gamblers were overrepresented in the group of respondents who selfreported that gambling advertising had a negative effect on them [40].

When it comes to social casino games, young people seem especially attracted to adverts using bright or contrasting colours and featuring animated characters [21]. Young people appear particularly susceptible to financial incentives [14, $20,41]$. Some children incorrectly thought that these financial incentives meant gamblers could never lose [42]. Moreover, some children misunderstood odds advertising, seeing these messages as merely providing relevant information, while misunderstanding the persuasive aspect of these adverts [43]. Additionally, children appeared to be attracted to the skill element of sports betting, and to bets with high odds [44]. Three-quarters of Australian children reported that they saw gambling advertising as a normal part of sport and could freely recall examples of financial incentives and odds advertising [45]. A qualitative study commissioned by the Advertising Standards Agency explored public perceptions of gambling advertising in the UK, with a specific focus on children's exposure [46]. Participants in this study also believed that children would find financial incentives advertising particularly persuasive. Another UK-based study found that recall of gambling advertising brands was high in a group of high school children [47]. 


\section{Gambling Marketing's Effect on Behaviour}

In order to quantify the influence of gambling marketing, several studies have sought to explore what association (if any) there is between awareness of, and participation with, gambling marketing and problematic gambling. A Norwegian study showed that problem gamblers were more likely to be aware of gambling marketing and to report that it increased their involvement in gambling [48]. Australian sports bettors, and in particular problem gamblers, who report taking advantage of advertised financial incentives appear to place more impulsive bets [49]. Problem gamblers in Norway also appear to be exposed to more gambling adverts than non-problem gamblers on social media [50]. Australian adolescents that gamble have been found to recall more gambling adverts than non-gamblers [51]. In a sample of young people (13-25 year olds) in Germany, gambling advertising recall was positively associated with gambling frequency [52]. An Ethiopian study similarly reported that gambling advertising may also contribute to problem gambling among adolescents [53]. However, one weakness is that retrospective studies can only measure gambling marketing recall. Any retrospective study will be biased if there are differential levels of recall bias between the two groups [54]. Plausibly, problem gamblers might simply remember more of the gambling marketing that they have been exposed to, therefore leading to an upwards bias in the measurement of this relationship.

One recent study attempted to overcome problems associated with self-reported data [55]. In this study, participants' betting behaviour and advertising exposure were tracked five times a week for three weeks. Advertising exposure was on average high and was followed by increased gambling expenditure for all groups of gamblers. A laboratory study by the same research team found that artificially-created financial incentives led to sports bettors taking on riskier bets and yet perceiving these bets to be lower risk. Furthermore, all gamblers on average underestimated the play-through requirements for these complex experimental financial incentives (gambling companies require a certain number of gambles to be made before financial incentives can be withdrawn). This set of studies provides some of the most convincing evidence yet on gambling advertising's negative effects on gamblers behaviour [55]. A follow-up to this study on messages sent direct to gambling account holder's mobile phones found that these 'push notifications' similarly prompted sports bettors to place larger and riskier bets [56].

\section{Conclusions}

The gambling marketing landscape changes quickly, and this review examined research conducted in the last five years, and since two previous reviews $[1,2]$. The studies reviewed suggest that gambling marketing content is highly targeted, both in terms of frequency and content, that many people have negative perceptions of gambling marketing, and that it may influence gambling-related knowledge, attitudes and behaviours. We reflect on the evidence covered by this review and offer recommendations for future research.

Gambling Marketing Content and Frequency Gambling marketing appears to be highly targeted and for those targeted (e.g. sports fans), it may be unavoidable. However, a second level of targeting is apparent in terms of advertising content. Financial incentives to gamble, for example, have become increasingly complex [22], in a way which gamblers may fail to understand correctly [55]. Odds advertising around British soccer targets complex high-margin bets $[27,28,30]$, in a way which soccer fans may also fail to understand correctly [30]. Some challenges for future research include systematically studying these aspects of targeted advertising and consumer misperception in other markets. In particular, we point to online and social media advertising as two research priorities $[17,19]$. Not only is more of our marketing exposure occurring online, but online marketing is also becoming increasingly challenging to measure, due to advertising being targeted on an individual level [15]. There are multiple stakeholders involved in online marketing, and it can be difficult to obtain representative samples of online advertising on certain platforms, such as Facebook or Google. The measurement of young people's [19], and vulnerable gamblers' [57] exposure to online and social media advertising is one future research priority.

Gambling Marketing Perceptions Perceptions of gambling marketing seem, overall, quite negative and are often worse for active gamblers than for the general population $[33,36$, 40]. Children also report being influenced by gambling marketing, such as financial incentives to gamble and odds advertising $[14,20,41]$, for instance misperceiving marketing about financial incentives to mean that gamblers could never lose $[42,43]$. However, there are also limitations inherent to any type of self-report data. People generally think that others will be more influenced by advertising than themselves [58], a 'third-person effect', with some evidence of this noted in gambling advertising [59]. As much of this work comes from Australia, research elsewhere is needed.

Gambling Marketing's Effect on Behaviour One key priority for future research is to address the relative lack of research on gambling marketing's effect on behaviour. Most research we reviewed exploring behaviour was based on self-report data. Some psychologists argue that many people are unaware of the true causal factors driving their behaviour in many situations [60]. Economists, meanwhile, are sceptical of any participant data which are not backed by incentive-compatible monetary bonuses to encourage truthful and reflective 
responses [61]. However, two recent studies on gambling advertising exposure and gambling behaviour provide some emerging evidence that advertising prompts more frequent and riskier gambling $[55,56]$.

Studies exploring gambling marketing's effect on behaviour raise some unique challenges. It can be challenging to recreate ecological scenarios of gambling marketing exposure and gambling behaviour in the laboratory. Gambling, like any risk-taking behaviour, is highly context dependent [62], and so laboratory scenarios may lack external validity. It can also be ethically challenging to put certain groups, for instance current or former problem gamblers, or young people, in realistic gambling scenarios. Cross-sectional and observational studies can provide a more naturalistic insight, but by design are limited in what inferences can be drawn: they can suggest associations between marketing exposure and effect, but cannot prove causality. Longitudinal studies can point to causality, but no studies using this design were identified in our review. The gambling industry and its advertising and marketing agencies also own data which could contribute to our understanding of the impacts of gambling marketing. This includes behavioural player data [63], advertising strategy documents, marketing briefs, campaign evaluation data and case studies, and we recommend that these should be made available to researchers $[64,65]$.

Attitudes towards gambling marketing appear to be changing. Recently, countries to restrict gambling advertising include Belgium [66] and Australia [67], with the Australian decision being based on the impact of daytime gambling advertising on children. The UK's biggest gambling companies have voluntarily agreed to stop gambling advertising around pre-watershed live sport [68], although the industry's total expenditure on online marketing is five times higher than TV advertising [69]. Italy, meanwhile, has scheduled a complete ban on gambling advertising, effective from 2019 [70]. Any informed legislative opinion should be based on the evidence which has been collected to date.

Acknowledgements The authors would like to thank Kathryn Angus, Research Information Specialist, for leading the electronic databases search for relevant literature.

Authors' Contributions All authors designed and/or conducted the study. PN created the first draft of the article. All authors revised and approved the final version of the article. The authors alone are responsible for the views expressed in this article, which do not necessarily represent the views, decisions or policies of the institutions with which they are affiliated.

Funding The study upon which this review is based was funded by GambleAware, a national charity instructed by government to commission research into gambling in Great Britain. GambleAware is funded through contributions from the gambling industry, but decisions about what research to fund are made by the Responsible Gambling Strategy Board (RGSB), an independent group that provides advice on gambling policy and research to government. In September 2016, the RGSB and
GambleAware published a Research Commissioning and Governance Procedure (www.rgsb.org.uk/PDF/Research-commissioning-andgovernance-procedure-September-2016.pdf) which describes how research priorities are set and commissioned, in isolation from the gambling industry.

\section{Compliance with Ethical Standards}

Conflict of Interest The authors declare that they have no conflicts of interest.

Human and Animal Rights and Informed Consent This article does not contain any studies with human or animal subjects performed by any of the authors.

Open Access This article is distributed under the terms of the Creative Commons Attribution 4.0 International License (http:// creativecommons.org/licenses/by/4.0/), which permits unrestricted use, distribution, and reproduction in any medium, provided you give appropriate credit to the original author(s) and the source, provide a link to the Creative Commons license, and indicate if changes were made.

Publisher's Note Springer Nature remains neutral with regard to jurisdictional claims in published maps and institutional affiliations.

\section{References}

1. Parke A, Harris A, Parke J, Rigbye J, Blaszczynski A. Responsible marketing and advertising in gambling: a critical review. The Journal of Gambling Business and Economics. 2015;8(3):21-35.

2. Binde P. Gambling advertising: a critical research review. London: Responsible Gambling Trust; 2014.

3. Duncan P, Davies R, Sweney M. Children 'bombarded' with betting adverts during World Cup. 2018; Available at: https://www. theguardian.com/media/2018/jul/15/children-bombarded-withbetting-adverts-during-world-cup, 2018.

4. Lopez-Gonzalez H, Griffiths MD. Betting, forex trading, and fantasy gaming sponsorships - a responsible marketing inquiry into the 'gamblification' of English football. Int J Ment Heal Addict. 2017.

5. Bunn C, Ireland R, Minton J, Holman D, Philpott M, Chambers S. Shirt sponsorship by gambling companies in the English and Scottish Premier Leagues: global reach and public health concerns. Soccer \& Society. 2018:1-12.

6. Cassidy R, Ovenden N. Frequency, duration and medium of advertisements for gambling and other risky products in commercial and public service broadcasts of English Premier League football. 2017; Available at: https://osf.io/gprkv/?action=download, 2017.

7. Lindsay S, Thomas S, Lewis S, Westberg K, Moodie R, Jones S. Eat, drink and gamble: marketing messages about 'risky' products in an Australian major sporting series. BMC Public Health. $2013 ; 13$

8. Hing N, Lamont M, Vitartas P, Fink E. Sports-embedded gambling promotions: a study of exposure, sports betting intention and problem gambling amongst adults. Int J Ment Heal Addict. 2015;13(1): 115-35.

9. Deans EG, Thomas SL, Daube M, Derevensky J, Gordon R. Creating symbolic cultures of consumption: an analysis of the content of sports wagering advertisements in Australia. BMC Public Health. 2016;16:208. 
10. Lopez-Gonzalez H, Guerrero-Solé F, Griffiths MD. A content analysis of how 'normal' sports betting behaviour is represented in gambling advertising. Addict Res Theory. 2017.

11. Lemarié L, Chebat J. Temptation and prevention provided by the gambling industry: main and interactive effects on gamblers. Recherche et Applications en Marketing (English Edition). 2015;30(4):51-63.

12. Lopez-Gonzalez H, Estévez A, Griffiths MD. Controlling the illusion of control: a grounded theory of sports betting advertising in the UK. Int Gambl Stud. 2018;18(1):39-55.

13. Johns R, Dale N, Alam SL, Keating B. Impact of gambling warning messages on advertising perceptions. 2017.

14. Gordon R, Chapman M. Brand community and sports betting in Australia. Victorian Responsible Gambling Foundation Melbourne, Australia; 2014.

15. Matz SC, Kosinski M, Nave G, Stillwell DJ. Psychological targeting as an effective approach to digital mass persuasion. Proc Natl Acad Sci U S A. 2017 Nov 28;114(48):12714-9.

16. Gambling Commission. Young people and gambling 2017: a research study among 11-16 year olds in Great Britain. 2017; Available at: https://www.gamblingcommission.gov.uk/PDF/ survey-data/Young-People-and-Gambling-2017-Report.pdf, 2018.

17. Thomas SL, Bestman A, Pitt H, Deans E, Randle MJ, Stoneham M, et al. The marketing of wagering on social media: an analysis of promotional content on YouTube, Twitter and Facebook. Victorian Responsible Gambling Foundation: Victoria; 2015.

18. O’Loughlin I, Blaszczynski A. Comparative effects of differing media presented advertisements on male youth gambling attitudes and intentions. Int J Ment Heal Addict. 2018:1-15.

19. Thomas SL, Bestman A, Pitt H, Cassidy R, McCarthy S, Nyemcsok $\mathrm{C}$, et al. Young people's awareness of the timing and placement of gambling advertising on traditional and social media platforms: a study of 11-16-year-olds in Australia. Harm Reduct J. 2018;15(51).

20. Kim HS, Wohl MJ, Gupta R, Derevensky JL. Why do young adults gamble online? A qualitative study of motivations to transition from social casino games to online gambling. Asian J Gambl Issues Public Health. 2017;7(1):6.

21. Abarbanel B, Gainsbury SM, King D, Hing N, Delfabbro PH. Gambling games on social platforms: how do advertisements for social casino games target young adults? Policy \& Internet. 2017;9(2):184-209.

22. Hing N, Sproston K, Brook K, Brading R. The structural features of sports and race betting inducements: issues for harm minimisation and consumer protection. J Gambl Stud. 2016:1-20.

23. Thaler RH, Johnson EJ. Gambling with the house money and trying to break even: the effects of prior outcomes on risky choice. Manag Sci. 1990;36(6):643-60.

24. Kahneman D, Tversky A. Prospect theory: an analysis of decision under risk. Econometrica. 1979;47(2):263-92.

25. Clark L, Lawrence AJ, Astley-Jones F, Gray N. Gambling nearmisses enhance motivation to gamble and recruit win-related brain circuitry. Neuron. 2009;61(3):481-90.

26. Reid R. The psychology of the near miss. J Gambl Behav. 1986;2(1):32-9.

27. Newall PWS. How bookies make your money. Judgm Decis Mak. 2015;10(3):225-31.

28. Newall PWS, Thobhani A, Walasek L, Meyer C. "Impulsiveness and urgency:" gambling advertising and the 2018 soccer World Cup. 2018; Available at: https://psyarxiv.com/3uc9s.

29. Cortis D. Expected values and variances in bookmaker payouts: a theoretical approach towards setting limits on odds. The Journal of Prediction Markets. 2015;9(1):1-14.

30. Newall PWS. Behavioral complexity of British gambling advertising. Addiction Research \& Theory 2017 02/05;25(6):505-511.

31. Committee of Advertising Practice. Regulatory statement: gambling advertising guidance. 2018; Available at: https://www.asa.org.uk/uploads/ assets/uploaded/5e19ecb5-a0b2-4322-aeb13047bb408298.pdf.
32. Tversky A, Kahneman D. Extensional versus intuitive reasoning: the conjunction fallacy in probability judgment. Psychol Rev. 1983;90(4):293-315.

33. Salonen AH, Hellman M, Latvala T, Castrén S. Gambling participation, gambling habits, gambling-related harm, and opinions on gambling advertising in Finland in 2016. Nordic Stud Alcohol Drugs. 2018;35(4):215-34.

34. Hing N, Cherney L, Blaszczynski A, Gainsbury SM, Lubman DI. Do advertising and promotions for online gambling increase gambling consumption? An exploratory study. Int Gambl Stud. 2014;14(3):394-409.

35. Hing N, Lamont M, Vitartas P, Fink E. Sports bettors' responses to sports-embedded gambling promotions: implications for compulsive consumption. J Bus Res. 2015;68(10):2057-66.

36. Hing N, Russell AMT, Lamont M, Vitartas P. Bet anywhere, anytime: an analysis of internet sports bettors' responses to gambling promotions during sports broadcasts by problem gambling severity. J Gambl Stud. 2017;33(4):1051-65.

37. Hing N, Vitartas P, Lamont M. Understanding persuasive attributes of sports betting advertisements: a conjoint analysis of selected elements. J Behav Addict. 2017;6(4):658-68.

38. Hing N, Russell AM, Vitartas P, Lamont M. Demographic, behavioural and normative risk factors for gambling problems amongst sports bettors. J Gambl Stud. 2016;32(2):625-41.

39. Lamont M, Hing N, Vitartas P. Affective response to gambling promotions during televised sport: a qualitative analysis. Sport Management Review. 2016;19(3):319-31.

40. Binde P, Romild U. Self-reported negative influence of gambling advertising in a Swedish population-based sample. J Gambl Stud. 2018;6.

41. Deans EG, Thomas SL, Derevensky J, Daube M. The influence of marketing on the sports betting attitudes and consumption behaviours of young men: implications for harm reduction and prevention strategies. Harm Reduct J. 2017;14(5).

42. Pitt H, Thomas SL, Bestman A, Daube M, Derevensky J. What do children observe and learn from televised sports betting advertisements? A qualitative study among Australian children. Aust N Z J Public Health. 2017;41(6):604-10.

43. Pitt H, Thomas SL, Bestman A. Initiation, influence, and impact: adolescents and parents discuss the marketing of gambling products during Australian sporting matches. BMC Public Health. 2016;16:967.

44. Pitt H, Thomas SL, Bestman A, Daube M, Derevensky J. Factors that influence children's gambling attitudes and consumption intentions: lessons for gambling harm prevention research, policies and advocacy strategies. Harm Reduct J. 2017;14(11).

45. Pitt H, Thomas SL, Bestman A, Stoneham M, Daube M. "It's just everywhere!" Children and parents discuss the marketing of sports wagering in Australia. Aust N Z J Public Health. 2016;40(5):480-6.

46. Research Works Limited. Public perceptions of gambling advertising in the UK. 2014; Available at: https://www.asa.org.uk/asset/ B6C18F98-B303-419F-9075397BB8808BD6/, 2018.

47. Wybron I. Reducing the odds: an education pilot to prevent gambling harm. 2018; Available at: https://www.demos.co.uk/wpcontent/uploads/2018/03/Reducing-the-Odds-an-Education-Pilotto-Prevent-Gambling-Harm.pdf, 2018.

48. Hanss D, Mentzoni RA, Griffiths MD, Pallesen S. The impact of gambling advertising: problem gamblers report stronger impacts on involvement, knowledge, and awareness than recreational gamblers. Psychol Addict Behav. 2015;29(2):483-91.

49. Hing N, Russell AM, Li E, Vitartas P. Does the uptake of wagering inducements predict impulse betting on sport? J Behav Addict. 2018;7(1):146-57.

50. Gainsbury SM, King DL, Russell AM, Delfabbro P, Derevensky J, Hing N. Exposure to and engagement with gambling marketing in social media: reported impacts on moderate-risk and problem gamblers. Psychol Addict Behav. 2016;30(2):270-6. 
51. Hing N, Vitartas P, Lamont M, Fink E. Adolescent exposure to gambling promotions during televised sport: an exploratory study of links with gambling intentions. Int Gambl Stud. 2014;14(3):374-93.

52. Clemens F, Hanewinkel R, Morgenstern M. Exposure to gambling advertisements and gambling behavior in young people. J Gambl Stud. 2017;33(1):1-13.

53. Abdi TA, Ruiter RA, Adal TA. Personal, social and environmental risk factors of problematic gambling among high school adolescents in Addis Ababa, Ethiopia. J Gambl Stud. 2015;31(1):59-72.

54. Coughlin SS. Recall bias in epidemiologic studies. J Clin Epidemiol. 1990;43(1):87-91.

55. Hing N, Russell A, Rockloff M, Browne M, Langham E, Li E, et al. Effects of wagering marketing on vulnerable adults. Victorian Responsible Gambling Foundation: Melbourne; 2018.

56. Hing N, Russell A, Rawat V. Direct messages received from wagering operators. Victorian Responsible Gambling Foundation: Melbourne; 2018.

57. Busby M. Revealed: how gambling industry targets poor people and ex-gamblers. 2017; Available at: https://www.theguardian. com/society/2017/aug/31/gambling-industry-third-partycompanies-online-casinos, 2018.

58. Davison WP. The third-person effect in communication. Public Opin Q. 1983;47(1):1-15.

59. Guerrero-Solé F, Lopez-Gonzalez H, Griffiths MD. Online gambling advertising and the third-person effect: a pilot study. International Journal of Cyber Behavior, Psychology and Learning (IJCBPL) 2017;7(2):15-30.

60. Nisbett RE, Wilson TD. Telling more than we can know: verbal reports on mental processes. Psychol Rev. 1977;84(3):231-59.

61. Bardsley N, Cubitt R, Loomes G, Moffat P, Starmer C, Sugden R. Experimental economics: rethinking the rules. New York: Princeton University Press; 2010.

62. Pedroni A, Frey R, Bruhin A, Dutilh G, Hertwig R, Rieskamp J. The risk elicitation puzzle. Nat Hum Behav. 2017;1(11):803-9.
63. Chagas BT, Gomes JF. Internet gambling: a critical review of behavioural tracking research. Journal of Gambling Issues. 2017;36.

64. Cassidy R, Loussouarn C, Pisac A. Fair game: producing gambling research - the goldsmiths report. London: Goldsmiths, University of London; 2013.

65. Newall PWS. Dark nudges in gambling. Addict Res Theory. 2018: $1-3$.

66. Simmons R. Belgium gambling advertising restrictions given goahead. 2017; Available at: https://www.gamblinginsider.com/news/ 4343/belgium-gambling-advertising-restrictions-given-go-ahead, 2018.

67. Toscano N, Duke J. Betting ads banned during live sport broadcasts. 2018; Available at: https://www.smh.com.au/business/ companies/betting-ads-banned-during-live-sport-broadcasts20180316-p4z4qq.html, 2018.

68. Kelner M. Gambling firms back ban on betting adverts during live TV sport. 2018; . Accessed https://news.sky.com/story/ban-on-inplay-tv-gambling-adverts-is-denied-as-betting-stocks-lose11573019, 2018.

69. GambleAware. Gambling companies spend $£ 1.2$ billion marketing online, five times more than on television ads. 2018; Available at: https://about.gambleaware.org/media/1857/2018-11-24-gamblingmarketing-online-five-times-tv-ad-spend.pdf, 2018.

70. Kelly T. Italy bans advertising on all forms of gambling as part of new 'dignity decree' after populist 5-Star leader said betting destroys families. 2018; Available at: https://www.dailymail.co.uk/ news/article-5921655/Italy-bans-gambling-adverts-Luigi-DiMaios-new-dignity-decree.html, 2018. 